\title{
Erratum to: One-stage bilateral versus unilateral short-stem total hip arthroplasty: comparison of migration patterns using "Ein-Bild-Roentgen-Analysis Femoral-Component-Analysis"
}

Karl Philipp Kutzner ${ }^{1} \cdot$ Tobias Freitag $^{2} \cdot$ Mark Predrag Kovacevic $^{1} \cdot$ Dominik Pfeil $^{1}$.

Heiko Reichel $^{2} \cdot$ Ralf Bieger $^{2}$

Published online: 22 April 2016

(C) SICOT aisbl 2016

Erratum to: International Orthopaedics (SICOT)

DOI 10.1007/s00264-016-3184-5

We highly regret that, unfortunately, a misspelling occurred in one of the names of our co-authors in the original publication, due to an oversight by the corresponding author in the correction process.

The correct spelling is:

Mark Predrag Kovacevic

The online version of the original article can be found at http://dx.doi.org/ 10.1007/s00264-016-3184-5.

Ralf Bieger

ralf.bieger@uni-ulm.de

1 Department of Orthopaedic Surgery and Traumatology,

St. Josefs Hospital Wiesbaden, Wiesbaden, Germany

2 Department of Orthopaedic Surgery, University of Ulm,

Oberer Eselsberg 45, 89081 Ulm, Germany 